\title{
Social Implications of New Mediated Spaces: The Need for a Rethought Design Approach
}

\author{
Antoine Zammit ${ }^{1(\bowtie)}\left(\mathbb{D}\right.$, Therese Kenna ${ }^{2}(\mathbb{D})$, \\ and Gabriela Maksymiuk ${ }^{3}$ (D) \\ ${ }^{1}$ Department of Spatial Planning and Infrastructure, \\ Faculty for the Built Environment, University of Malta, Msida, Malta \\ antoine.zammit@um.edu.mt \\ 2 Department of Geography, University College Cork, Cork, Ireland \\ t.kenna@ucc.ie \\ 3 Department of Landscape Architecture, University of Life Sciences, SGGW, \\ Warsaw, Poland \\ gabriela_maksymiuk@sggw.pl
}

\begin{abstract}
Departing from the traditional understanding of the social implications of urban design and the underlying notion of 'place', the chapter first questions its current relevance vis-à-vis the mediated city. It examines whether ICT has given rise to the establishment of new notions of space and place, identifying new design challenges for cities and rethought approaches to the production of space. In view of the latter, the chapter subsequently questions the manner with which digital media may facilitate inclusive design of public spaces. In order to address this objective, the chapter illustrates some interesting empirical data emanating from literature and research projects based in the UK, Poland and Malta. The case studies in the literature illustrate how ICTs are being used as tools within participatory processes for the inclusive design of urban public and recreational spaces and in order to gauge citizen/user expectations towards urban space. The chapter finally attempts to redefine public participation through ICT and to frame the above discussion within the potentially newly redefined role of urban designers involved in such processes. The underlying question to be addressed in this chapter, therefore, has to deal with the manner with which urban professionals may effectively achieve inclusive participatory design, particularly in light of new phenomena brought about by the mediated city and with the potential of this newly obtained and enriched data.
\end{abstract}

Keywords: Mediated open spaces $\cdot$ Participatory planning processes $\cdot$ Inclusive design $\cdot$ Place $\cdot$ P-GIS $\cdot$ SoftGIS $\cdot$ PPGIS

\section{Introduction}

Urban design theories that flourished between the 1960s and 1980s were particularly concerned with the social dimension of urban design - some born through the necessity of addressing social and economic inequalities in cities (Jacobs 1961), others seeking to 
understand the social life of urban spaces (Whyte 1980) and others still seeking to redefine and reconceptualise the notion of space in social terms (Lefebvre 1991). The discussion is still central to the urban design agenda today. Numerous authors discuss the social processes, both "formal and informal [...] that shape the urban environment" (Tonkiss 2013: 1) and, therefore, the indelible relationship between the physical urban space and social practices. This relates to the deeper understanding of place making and its significance in creating quality urban environments that relate to broader quality of life considerations.

\section{Changing Notions of Space and Place Within the Mediated City}

The reshaping of public spaces by mass media goes back to the early 19 th century. The introduction of newspapers activated public spaces in new ways, and cafés became hubs for community building by providing a space for information exchange and dialogue. With the rise of the consumer culture, new public spaces were created that were linked with shopping and entertainment (Riether 2010) and with an increasing role for media therein. As ICTs continue to change our social dynamics, they simultaneously modify the space that we use daily.

Aurigi (2005b) argues that new virtual spaces brought about by ICT may indeed possibly replace human interaction as traditionally occurring within urban spaces, in turn generating a new form of urbanism. Other authors, such as Graham and Marvin (1999, in Carmona et al. 2008), contend quite the opposite - arguing that in actual fact the traditional city is being reinforced even more as people working in IT increasingly opt to live in urban areas in order to maintain important human contact. Carmona et al. (2008) further argue that the need for face-to-face communication remains, reinforced by the increasing role of 'third place spaces'. At the same time, such face-to-face interaction within physical places occurs in tandem with so-called "“distant proximities" of socialities that are mediated by ICTs" (Waltz, 2002 in Graham 2004: 241), which are not necessarily less rich or meaningful than physical encounters. These issues are heightened when one considers the new design challenges brought about by ICT.

\subsection{The New Design Challenges}

The intensive use of Internet and other digital technologies over the last two decades has caused urban public space to transition from its (traditional) dual social role as instrumental (providing a physical link between architecture and land-uses) and expressive (facilitating a link between people, thus serving as places for social interaction) (Stadler 2013). ICT is today deeply rooted in the urban fabric of contemporary cities worldwide (Bibri and Krogstie 2017).

Modern cities face a number of challenges including population growth, environmental pressures, socio-economic and socio-cultural changes and unpredictable phenomena. As more people move towards urban cities, there is increasing pressure on resources and capacity. ICTs can allow for more innovative ways to make better use of existing space, thus help manage resources more efficiently. Cities must be dynamic in 
their conception, flexibly planned, scalable in their design and efficient in their operations, and all these actions rely to a large extent on ICT and its presence in urban systems (Bibri and Krogstie 2017). Undoubtedly, at the strategic scale of the city, ICT has had major spatial implications. Research on the development of ICT in urban contexts and on the 'cyber' dimension of cities reveals that, today, major urban functions and activities have been blurred into almost any place in the city (Malecki 2017).

A number of spatial scientists (including Aurigi 2005a; Stadler 2013; and Malecki 2017) concur that the key design challenges for urban public spaces that must be addressed include:

1. a problem of 'scale' (as with ubiquitous ICT usage the city is more than a physical space);

2. public spaces' accessibility issues (as the contribution of ICTs to counteract social inclusion in public spaces is highly controversial);

3. issues of visibility vs. invisibility (as display technologies scatter urban landscape, while ICTs are believed to be largely invisible); and

4. issues of physical vs. virtual (as online delivery of certain urban services is held responsible for interrupting the spirit of public spaces, especially streets).

ICT has the potential to convert public space into a highly interactive environment wherein the observer is also the participant in the collection and distribution of information. In turn, this may produce a new type of public space that is characterised by an active interchange between virtual and real spaces (Riether 2010). This necessitates a deeper understanding of the process that is leading to the production of physical space.

\subsection{The Production of Space}

Authors concur that 'social space' forms with each societal member's specific relationship to the physical space (Lefebvre 1991). Its shaping requires, therefore, the input of each citizen within the process leading to the physical product that is urban space. Indeed, implicit to the discussion of public space and place making is the notion of inclusive urban spaces.

A number of social movements have also spurred a newly found attitude towards citizen empowerment and bottom-up participatory planning - issues that have become more pronounced with privatisation (and neoliberal urban policy) that has changed the nature of urban public space over the past decades. Some readers may consider the above themes to be overly debated; nevertheless, they provide an important prelude to a deeper discussion as they have taken on a new dimension in the face of the mediated city. ICTs may provide an added value to design and planning processes - today's technologies may aid researchers in their study of people interacting with urban spaces, through the application of important digital tools that collect and analyse data.

At the same time, research has also drawn attention to the fact that ICTs may be enhancing or widening already-existing social and economic inequalities in the city, due to the digital divide or the lack of access to technology (Kruger 1997; Graham 2004). This may have a detrimental effect on individuals, instilling a feeling of 
disempowerment and alienation from the rest of society, which in turn would reinforce existing exclusionary patterns. Kruger (1997) illustrates this through a discussion of the electronic business culture and its tendency to be targeted towards specific sectors of the population on the basis of affluence and social status. Graham (2004) further argues that, particularly through sorting software techniques, specific users are identified, targeted and marginalised as attractive or risky, profitable or not.

The other important aspect is that the more traditional understanding of 'community' and 'place' merits considerable rethinking, as these terms are not solely territorially defined. This, therefore, requires an acknowledgement that moves beyond a (limited) physical understanding of these terms.

The transformation of urban space is challenging new forms of interaction between different social actors and digital media. The new urban setting encompasses the widespread availability of data and, as discussed above, the opportunities for citizens to be the leaders, as well as the objective, of urban innovation (Cook et al. 2015). Clearly, new strategies for citizen engagement and bottom-up planning and design practices, themselves redefined through the possibilities offered by ICT, need to increasingly develop sensitivities to any possible inequalities to be accessible to all. It is to this important theme that our attention now turns.

\section{Inclusive Approaches in the Mediated City}

Over the past two decades, urban designers, together with other urban professionals such as urban planners, have paid increasing attention to the issues of participation and inclusion in their professional practice after calls to move away from top-down urban design and planning, towards more bottom-up approaches (Watson 2014). Indeed, how the state, and the various professional organisations involved in urban design and development, relate to society and the public has been one of the more prominent themes in the academic literature (Watson 2014). These recent calls were not just for a more inclusive or participatory design process; they were also aimed at encouraging greater focus on the people who use the city - a people-centred approach (Gehl 2010).

As a result of these calls, over the last few decades, urban designers have sought to closely align themselves with the future users of the urban spaces and products they design. This alignment, or relationship with the users, has occurred in differing ways (Sanders and Stappers 2008). The first was a user-centred design approach, with the user seen as a subject. Here, design occurs from the perspective of an expert whereby "trained researchers observe and/or interview largely passive users, whose contribution is to perform instructed tasks and/or to give their opinions about product concepts that were generated by others" (Sanders and Stappers 2008: 5). Under this style of urban design, users are included, but are generally passive participants, offering their thoughts or opinions on already-formed ideas. Secondly, and mostly in European circles, the participatory approach (user as partner) became increasingly prominent in urban design during the 1970s. Under this model of urban design, people - the users - were "given more influence and room for initiative in roles where they provide expertise and participate in the informing, ideating, and conceptualising activities in the early design phases" (Sanders and Stappers 2008: 5). The participatory approach allows for the 
users of the future urban spaces to be included in the design process, especially in relation to the final product. However, the user-centred design approach began to lose appeal as it was deemed that the approach could not "address the scale or the complexity of the challenges we face today" (Sanders and Stappers 2008: 10) and this is where more rounded participatory approaches, such as co-design began to fill the void, defined as:

[...] any act of collective creativity, i.e. creativity that is shared by two or more people. By co-design we indicate collective creativity as it is applied across the whole span of a design process [...] a specific instance of co-creation. (Sanders and Stappers 2008: 6)

This shift in discourse and terminology to 'co-creation' and 'co-design' within the urban design profession is to ensure that the application of participatory design practices occurs "both at the moment of idea generation and continuing throughout the design process at all key moments of decision" (Sanders and Stappers 2008: 9). It is believed that this will ultimately reflect a 'true' participation by users and all relevant stakeholder groups.

While the approaches of co-creation and co-design have gained considerable support and traction over the last two decades, they are not without flaws. As Sanders and Stappers (2008) highlight, some co-design approaches can be highly selective in terms of the inclusion of users.

With the rapid infusion of ICTs in our personal and professional lives, ICTs present a possible new method for enhancing co-design of urban spaces and for creating wider participation from users. Lim et al. (2016) argue that "the innovations of the twentyfirst century in digital technology and media have had major influences in the way young urbanites and future city designers think as well as experience places" (Lim et al. 2016: 638).

A range of new digital and information communication technologies are entering the field of urban design and planning, creating new possibilities for inclusion and cocreation in the urban design process. Fredericks and Foth (2013) note that social media sites such as Twitter and Facebook have "grown beyond the purely 'social' realm and [are] now increasingly used to cause real impact, in terms of community activism, civic engagement, cultural citizenship and user-led innovation" (Fredericks and Foth 2013: 245). Furthermore, Evans-Cowley and Hollander (2010) suggest that research on online citizen participation has demonstrated that ICT tools can work to enhance public participation, so much so that in certain neighbourhoods or communities, "there is a growing expectation on the part of citizens that there will be online participation opportunities" (Evans-Cowley and Hollander 2010: 399). ICT-mediated participation is therefore not something that is solely seen to be desirable; rather, it seen to be essential by certain sections of the community.

In recent years, planning practitioners have begun to comprehend the importance of incorporating more inclusive methods into their work. The most commonly used method is participatory mapping with a physical map and space for discussion. Now ICTs are used to facilitate and advance the process. Most notably, there is a growing interest in using participatory geographic information systems (P-GIS) to engage the public. Numerous international examples show that GIS can be used not only for planning and managing the city, but also for including the residents in these processes 
(Goodchild and Glennon 2010; Haklay 2010). The objective is to integrate bottom-up processes in the domain of urban planning, using the full potential of citizens by sharing ideas in the co-production of decision making. Therefore, the relationship between decision-makers and their respective communities is continuously evolving from closed, top-down approaches into a more interactive exchange.

The following sections discuss three examples from the UK, Poland and Malta illustrating the implementation of digital tools that seek to enhance ICT-mediated participation.

\subsection{Participatory GIS in UK Cities: Improving Participation in Urban Design}

Recent work from three cities in the UK by Cinderby (2010) sought to understand how Participatory Geographic Information Systems (P-GIS) could be used for more inclusive urban design. A particular focus of the research was on whether or not these new ICT tools could improve the participation of 'hard-to-reach' communities, which includes (though not limited to) people from Black Minority Ethnic communities, asylum seekers, people with disabilities, young people, older people and people living in deprivation or on low incomes. Part of the rationale for this focus was that the use of traditional methods of participation (such as open public meetings) "fail to reach significant segments of communities" (Cinderby 2010: 239). The study sought to examine whether P-GIS was an efficient tool to overcome the barriers to engagement experienced by the aforementioned groups with the more traditional methods of participation. Three case studies were used: a health walk development in the inner city of Salford, UK; public perceptions of streets and squares in the city centre of York, UK; and the development of transport options for one of the suburbs of Blackpool, UK (Cinderby 2010).

The research identified a range of problems that might be causing a lack of engagement from certain groups, including: "language barriers, cultural differences, time and ability to attend public meetings even if they were interested in the issue" (Cinderby 2010: 240). P-GIS was explored as a way of overcoming barriers and challenges such as these. Cinderby (2010) discusses the utility of P-GIS "to capture local stakeholder knowledge" (Cinderby 2010: 240), arguing that "[t]he visual nature of participatory mapping removes, to some extent, the barriers of literacy and, to a degree, language [...] that other forms of engagement, such as focus groups or questionnaires, require" (Cinderby 2010: 240). In this manner, importantly, maps become the central element, transcending issues such as the presence of specific individuals who might take over during public debates and meetings.

From the outset, this form of participatory engagement with mapping is viewed to overcome barriers to engagement for a range of social groups. In the case study areas, the researchers were involved in on-street engagement with participants. They used a series of on-street events to take the mapping exercise to their participants, so as to overcome issues of access to digital technologies such as computers and the Internet. 
For example, in the Salford case study, the on-street events were held at "a health centre, alongside a parade of local shops and at a community fun-day event" (Cinderby 2010: 240). In this manner, "these venues allowed pensioners, children, teenagers and young adults from a low-income community to communicate their local knowledge and preferences for the proposed walking route to the research team" (Cinderby 2010: 241). From these on-street events, there were 120 participants and 200 comments, a quarter of which were from hard-to-reach groups, particularly children and teenagers.

The team identified a number of advantages to the on-street approach: participants did not need to make special arrangements for childcare, transport, and the like; the time involved was less than $15 \mathrm{~min}$; the one-on-one conversations between the researcher and the participant meant that participants did not have to justify their comments to their peers (as might be the case in open public meetings); and "the use of in-situ on-street mapping allowed people to physically engage with the area in a way that would be impossible using conventional approaches" (Cinderby 2010: 241-242). In all, this brief discussion illustrates that in certain circumstances, the use of technologies and participatory approaches can work to overcome some of the challenges relating to the inclusion of 'hard-to-reach' groups and thus widen participation in urban planning and design processes.

\subsection{SoftGIS in Participatory Management of Natural Areas in Polish Cities}

Poland's political and economic transformation in the 1990s, which was characterised by a shift from a centrally planned economy into a market economy, and the introduction of democracy, resulted in many achievements including a more bottom-up approach in governance. At the city level this process is actualised through engaging citizens to be involved in planning and management of public spaces and the introduction of participatory budgets allowing residents to propose projects and later on nominate those for realisation through official voting. Many of those projects deal with green urban spaces and public spaces. However, a civic awareness and sense of shared responsibility for urban space is still not fully developed, and there are certain groups of citizens that are not interested in participation at all (Maksymiuk and Kimic 2016) a 'non-engagement' attitude that is deeply rooted in the history of a post-Soviet society. At the same time, in most Polish cities, the local authorities strive to involve dwellers in local affairs; however, the traditional methods of participation seem to be insufficient. The question, therefore, is whether the application of new technologies may enhance the level of residents' involvement in issues related to the co-design of public spaces.

Since most decisions on nature in cities have a spatial dimension, the application of GIS offers a notable potential for public participation (Czepkiewicz 2013). Recent research in three Polish cities carried out by the Sendzimir Foundation (2015), similar to Cinderby's (2010) work in the UK discussed previously, dealt with the applicability of the SoftGIS methodology to study residents' perception of urban green spaces and to crowdsource their ideas and opinions on public spaces in their cities or neighbourhoods. 


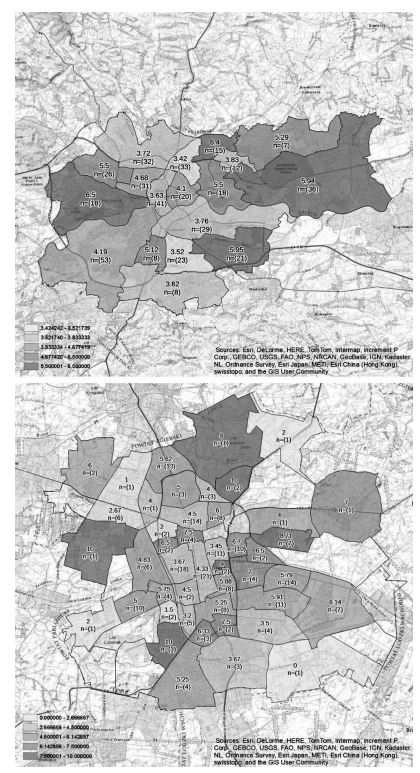

Fig. 1. Example of geo-questionnaire applied in the "Count on green" project. Results for assessment of green spaces in regards to their potential for recreational and social integration (Cracow - upper image, Lodz - bottom image). Source: Data derived from Fundacja Sendzimira is licensed under a Creative Commons Attribution 4.0 International License.

The SoftGIS methodology enables a researcher to conduct a quantitative social research, using geo questionnaires (linking internet maps and questionnaires), followed by spatial and statistical analysis, and communicating the outcomes to planners and officials. In this way, the SoftGIS allows the everyday knowledge and point of views of residents, soft data, to be added to hard data about infrastructure (Report from the Project 'Count On Green' 2015). The 'Count On Green' project resulted in around 12,500 spatial indications emanating from more than 1,600 filled questionnaires that appeared on interactive maps of greenery in three Polish cities - Cracov, Łódź and Poznań (Fig. 1).

The main research focus was to collect data that could be useful for the management of green areas in each city, but also to test the SoftGIS methodology. The residents supplied information on their favourite urban green spaces, preferred walking routes, areas requiring better maintenance, top city districts (in term of liveability) and they indicated the most neglected neighbourhoods. The project was advertised online through social media channels and was also promoted alongside open cultural and recreational events in the three cities under study. The residents could share their opinions via an online platform. In addition, 50 volunteers gathered data about greenery using tablets during various events for a total of $480 \mathrm{~h}$. In general, the participation of younger adults was much wider and, while it was observed that older residents rejected the active use of new technologies on their own, they were nevertheless very receptive towards volunteers with tablets, who approached the residents 
individually and who helped to add the data to the maps. The local authorities of all three cities eagerly accepted the results of the project. The above example illustrates how research methods using digital tools such as SoftGIS may be utilised in different ways - to first generate data on a specific topic, but also to encourage public participation among the younger generation who would otherwise avoid traditional ways of public participation, such as public meetings or having to send written comments by mail.

\subsection{Public Participation GIS in Valletta, Malta: Hybridity in Citizen Participation}

Public Participation GIS (PPGIS) was used in Valletta to assess the impact of cultural infrastructure generated by the European Capital of Culture 2018, as seen through the eyes of its citizens and visitors. This research stage is part of a larger five-year study that investigates the socio-spatial impacts of culture-led regeneration through the inclusion of new cultural infrastructure. Understanding the relationship between physical interventions and social changes enables researchers to examine different dimensions that concern broader liveability and quality of life considerations (Zammit 2018).

The research centres on four pre-selected sites in the Capital chosen as pilot regeneration projects, geographically spread around Valletta's territory and led by different public and private stakeholders. In particular, the study centres on the analysis of impact due to change of uses on the surrounding neighbourhoods, with an interest in the commercialisation of buildings and urban spaces that in turn has strong implications for residential amenity. For this reason, it was imperative to obtain an in-depth understanding of participants' views, concerns and future aspirations for each of the four neighbourhoods. PPGIS may provide a potentially rich dataset in this regard (Zammit 2018).

In collaboration with Mapping for Change - a social enterprise within University College London - a 'communitymaps' interface was adapted for use in the Maltese Islands. The PPGIS was first piloted in a workshop held in December 2016. A few months earlier, another residents workshop (Design4DCity), had been held in Valletta that yielded key themes, which were chosen for the streamlined digital online interface. The latter was tested with the participating residents through their personal devices, followed by a physical mapping session. Participants remarked that the digital mapping was more useful when it was preceded by a face-to-face communal discussion whilst mapping elements of the discussion on a physical map.

A participatory mapping walkabout around the sites was subsequently held in November 2017. The objective was to integrate the participatory mapping system to the Design4DCity themes. Participants were presented with a paper map showing both the site to be mapped, spaces within which to jot down comments and details of how to use the online platform (Fig. 2). 

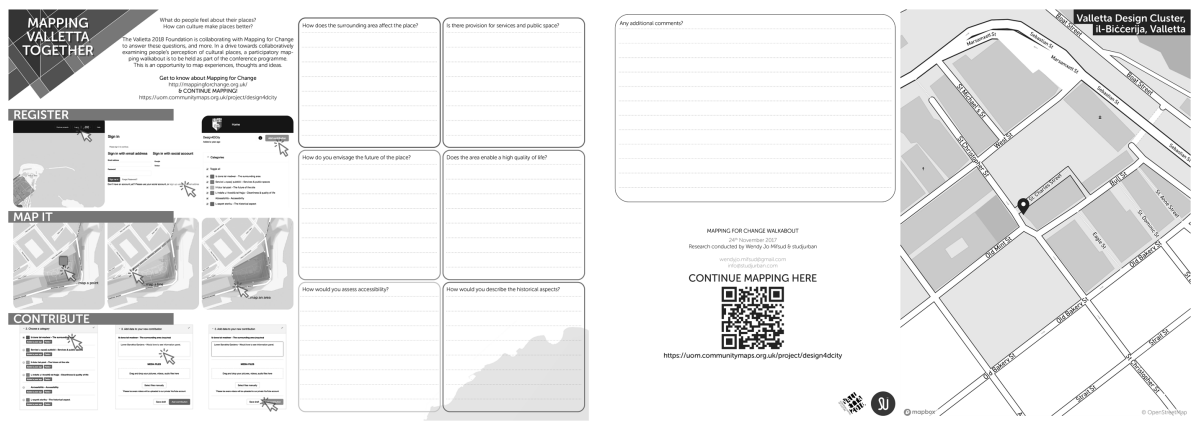

Fig. 2. Sample of paper map used by PPGIS participants during the mapping exercise carried out in one of the four Valletta neighbourhoods, the Biccerija. Source: studjurban.

The participants were broadly briefed on these themes as well as the importance of their open-ended participation in data gathering. Limiting the themes to be observed by the participants provided more definitive responses that could be free of any influence and bias from the project coordinators. Following the PPGIS walkabout the hundreds of collected responses were digitised and mapped (Fig. 3). Around a third of the participants were able to map their observations during the walkabout immediately onto the online platform and most of them also used the paper mapping method; thereby combining both physical and digital participatory mapping. The session ran for around an hour and enabled the participants to engage with the coordinators and fellow participants, as well as with members of the public. It was observed that although the physical map provides a context for discussion, participants are not always easily adapted to the technology. Those who faced challenges with Internet access carried out the mapping manually on paper.

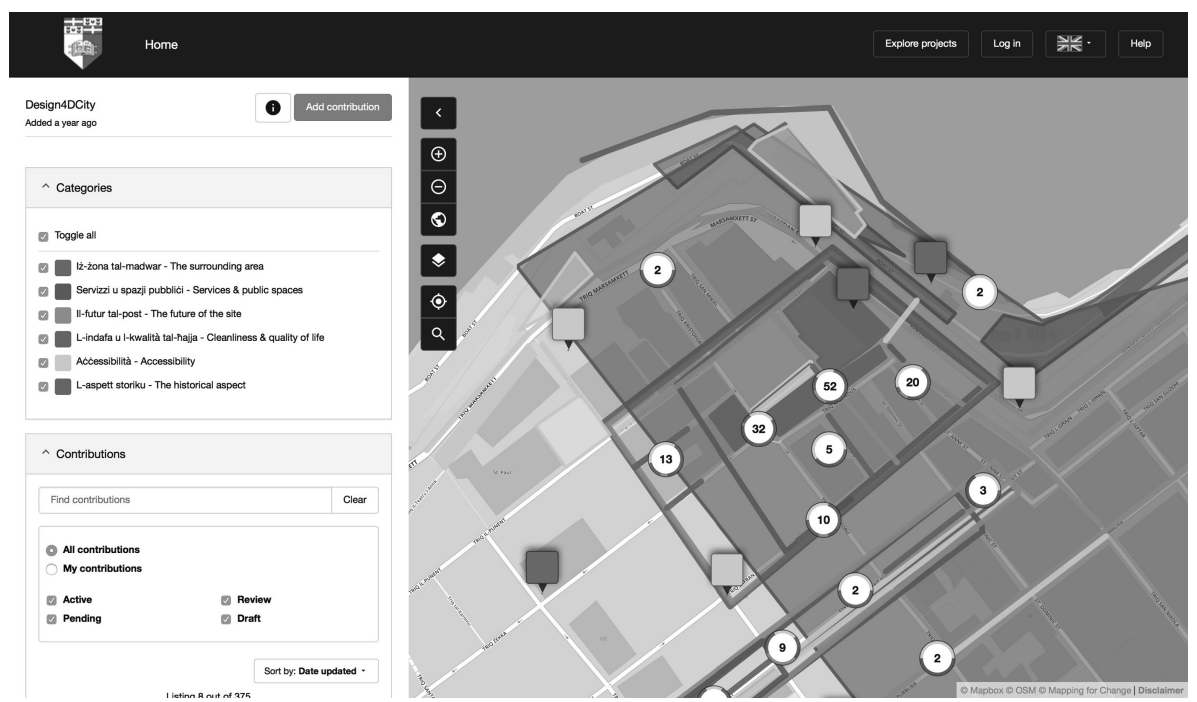

Fig. 3. Digital mapping of PPGIS responses. Source: https://uom.communitymaps.org.uk/ project/design4dcity 
Key repeated observations were extracted for the four sites, which consequently permitted further extraction of themes from participant responses to create specific categories for numerical evaluation. The data for the four sites was subsequently overlaid for comparative analysis and results from previous stages of the research, based on an analytical framework using criteria for the same themes, were compared to those extracted from the PPGIS.

\subsection{Concluding Thoughts from the Three Examples}

The awareness of communities' conflicting interests is important for all policy areas to be able to find common understanding and solutions to all needs. In the case of urban planning, there are additional challenges since participants, whether urban planners or citizens, need to comprehend and envision undeveloped urban spaces. Participants thus need to analyse the primary values and needs of a community, and in addition translate abstract ideas about physical space into specific proposals (Gordon and Manosevitch 2011). The introduction of powerful new ICT tools has made this visualisation possible and easily accessible to the public. It has also opened communication within the public and private sector, therefore changing the conventional systems and relations of governance and citizenship. ICTs have enabled citizens to have a more active role in public service. Consequently, public participation has become vital to the land use planning processes.

From the three examples discussed above we may extract the following salient points:

- The importance of the visual nature of participatory mapping that offsets literacy and language barriers.

- The map as the central participatory element, and the possibility of everyone equally accessing such map rather than select individuals, thus overcoming possible barriers to engagement.

- The need for participatory planning to happen close to home - either in the areas under analysis, or next to known places that the community may relate to and that are easily accessible for all.

- Technology is a much more effective tool for youths than public meetings or written submissions, while older participants still require face-to-face interaction which may nonetheless co-exist with technology.

- The utility of physical mapping and the need to complement the digital mapping process with a physical one, and following up with face-to-face discussions.

The examples discussed above are characterised by a combination of formal and informal social structures in terms of the power and control in institutional settings: in each case, there are the participants, researchers and policy makers. Involving nonprofessionals in mapping should not exclude the role of professionals, as it is needed for guidance and to assist with analysis. 


\section{Concluding Thoughts}

\subsection{Redefining Public Participation Through ICT}

Public participation may be achieved through different levels of public engagement. Digital tools, including GIS, may be applied at any level of the participation spectrum, from informing, through consulting, engagement, cooperation, up to empowerment (International Association for Public Participation, 2007). Similarly, Nobre (1999, cited in Laurini 2001) outlines four levels of community participation that represent the different scales of involving the public in the planning process: to inform, to consult, to discuss and to share. The higher levels of participation require two-way interaction as the public's feedback plays a role in the decision-making process. Sharing power decision-making, that is empowering communities, is the highest level of community participation.

It is at this level that ICT really becomes a game-changer. Gordon and Manosevitch (2011) introduce augmented deliberation as a "possible design solution that addresses uniquely difficult contexts where deliberation is complicated by external factors" (Gordon and Manosevitch 2011: 80). In addition, augmented deliberation can potentially transcend other critical challenges that are normally commonplace and that hinder the achievement of these higher levels of participation, including language barriers, power differentials, and other communication challenges. It is here that ICTs seem to present one of the greatest opportunities for urban planning and design - the inclusion of social groups that would otherwise not engage in planning and design processes and decision making. The use of ICTs, such as in participatory GIS, can ensure that urban professionals are not simply producing urban spaces (in historically top-down ways) but rather they are more effectively co-producing and co-designing urban space, which will ultimately ensure that urban public spaces are designed for diverse users and diverse needs.

\subsection{A Redefined Role for Urban Designers}

ICTs are becoming more and more integrated with our daily lives. They are bringing about new social behaviours that directly impact the way users interact with their physical surroundings, including how people interact in public spaces. Alongside diminishing the usual interaction between people, technology has introduced a new type of public life. Social media has allowed short term and temporary public life with its instant messages to large audiences, drawing a mass of people to use an urban private or public space for a short period of time. Simultaneously, traditional spaces are being challenged to rethink the desire for new social interaction, as discussed above. This is redefining the roles of design professionals, which requires them to think more comprehensively and inclusively.

These continuous trend changes have challenged the conventional role of urban designers. They can no longer deal with urban fabric as static systems but instead need to adapt a multidisciplinary way of planning that combines traditional design skills with a modern understanding of society's current behaviour (Southworth 2014). Creative rethinking has become a crucial design tool, as cities must become experiment grounds 
to improve the residents' wellbeing as they continue to expand and grow. The need to merge conventional problem-solving planning tactics with ICTs is becoming a necessity.

It is evident that the opportunities and challenges brought about by ICT demand the engagement of multiple actors in the creation and activation of mediated urban spaces. In between the top-down approaches (needed for structural changes and planning of future investment in ICT) and bottom-up, participatory and inclusive initiatives, the urban designer has the potential to become a central figure, enabling and empowering communities using digital tools to overcome traditional barriers and ensuring the inclusion of this invaluable input in the preparation of strategies, objectives and tangible design outcomes for the mediated city.

\section{References}

Aurigi, A.: Tensions in the digital city. Town Country Plan. J. 74, 143-145 (2005a)

Aurigi, A.: Making the Digital City: The Early Shaping of Urban Internet Space. Ashgate, London (2005b)

Bibri, S.E., Krogstie, J.: Smart sustainable cities of the future: an extensive interdisciplinary literature review. Sustain. Cities Soc. 31, 183-212 (2017)

Carmona, M., de Magalhães, C., Hammond, L.: Public Space: The Management Dimension. Routledge, Oxon (2008)

Cinderby, S.: How to reach the 'hard-to-reach': the development of Participatory Geographic Information Systems (P-GIS) for inclusive urban design in UK cities. Area 42(2), 239-251 (2010)

Cook, J., Lander, R., Flaxton, T.: The zone of possibility in citizen led hybrid cities. In: Workshop on Smart Learning Ecosystems in Smart Regions and Cities, 15 September 2015, Toledo, Spain (2015)

Czepkiewicz, M.: Systemy informacji geograficznej w partycypacyjnym zarządzaniu przyrodą w mieście. In: Zrównoważony rozwój - Zastosowania nr 4 (2013)

Evans-Cowley, J., Hollander, J.: The new generation of public participation: internet-based participation tools. Plan. Pract. Res. 25(3), 397-408 (2010)

Fredericks, J., Foth, M.: Augmenting public participation: enhancing planning outcomes through the use of social media and web 2.0. Aust. Plan. 50(3), 244-256 (2013)

Gehl, J.: Cities for People. Island Press, Washington, DC (2010)

Goodchild, M.F., Glennon, J.A.: Crowdsourcing geographic information for disaster response: a research frontier. Int. J. Digit. Earth 3(3), 231-241 (2010)

Gordon, E., Manosevitch, E.: Augmented deliberation: merging physical and virtual interaction to engage communities in urban planning. New Media Soc. 13(1), 75-95 (2011)

Graham, S.: The software-sorted city: rethinking the "digital divide". In: Graham, S. (ed.) The Cybercities Reader, pp. 324-331. Routledge, Oxon (2004)

Haklay, M.: How good is volunteered geographical information? A comparative study of OpenStreetMap and Ordnance Survey datasets. Environ. Plan. B: Plan. Des. 37(4), 682-703 (2010)

International Association for Public Participation: Spectrum of Public Participation (2007). http:// www.iap2.org/associations/4748/files/spectrum.pdf. Accessed 5 July 2017

Jacobs, J.: The Death and Life of Great American Cities. Vintage Books, London (1961) 
Kruger, D.: Access denied. In: Graham, S. (ed.) The Cybercities Reader, pp. 320-323. Routledge, Oxon $(1997,2004)$

Laurini, R.: Information Systems for Urban Planning: A Hypermedia Cooperative Approach. Taylor \& Francis, London (2001)

Lefebvre, H.: The Production of Space. Blackwell Publishing, Malden (1991). English translation/version (Translated by Donald Nicholson-Smith)

Lim, R.M., Azevedo, L.N., Cooper, J.: Embracing the conceptual shift on new ways of experiencing the city and learning urban design: pedagogical methods and digital technologies. J. Urban Des. 21(5), 638-660 (2016)

Maksymiuk, G., Kimic, K.: Green projects' in participatory budgets inclusive initiatives for creating city's top quality public spaces. Warsaw case study. In: Marina, O., Armando, A. (eds.) Inclusive/ Exclusive Cities, Skopje (2016)

Malecki, E.: Real people, virtual places, and the spaces in between. Socio-Econ. Plan. Sci. 58 (2017), 3-12 (2017)

Report From the Project 'Count On Green': A fresh look at greenery. Geo-questionnaires: a new source of information about a city, Sendzimir Foundation, p. 11 (2015)

Riether, G.: Digital phantasmagoria: an urban space of intensified interaction. In: SIGRID 2010, Bogota (2010)

Sanders, E.B.-N., Stappers, P.J.: Co-creation and the new landscapes of design. Co-Design 4(1), 5-18 (2008)

Southworth, M.: Public life, public space, and the changing art of city design. J. Urban Des. 19 (1), 37-40 (2014)

Stadler, R.L.: ICTS as a tool to increase the attractiveness of public spaces, K. Šešelgis' Readings - 2013. 5(3), 216-228 (2013). https://doi.org/10.3846/mla.2013.39

Tonkiss, F.: Cities By Design: The Social Life of Urban Form. Polity Press, Cambridge (2013)

Watson, V.: Co-production and collaboration in planning - the difference. Plan. Theory Pract. 15 (1), 62-76 (2014)

Whyte, W.H.: The Social Life of Small Urban Spaces. Project for Public Spaces, New York (1980)

Zammit, A.: Assessing the relationship between community inclusion and space through Valletta 2018 cultural infrastructural projects. In: Valletta 2018 Foundation Evaluation and Monitoring. Research Findings 2017 - Theme 3: Community Inclusion and Space, Malta, pp. 21-35 (2018)

Open Access This chapter is licensed under the terms of the Creative Commons Attribution 4.0 International License (http://creativecommons.org/licenses/by/4.0/), which permits use, sharing, adaptation, distribution and reproduction in any medium or format, as long as you give appropriate credit to the original author(s) and the source, provide a link to the Creative Commons license and indicate if changes were made.

The images or other third party material in this chapter are included in the chapter's Creative Commons license, unless indicated otherwise in a credit line to the material. If material is not included in the chapter's Creative Commons license and your intended use is not permitted by statutory regulation or exceeds the permitted use, you will need to obtain permission directly from the copyright holder.

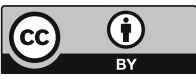

